\title{
On the Study of the Spatio-Temporal Variations in Intensity of 30 - 60-Day Intraseasonal Rainfall Oscillations in Central Africa Using Wavelet-Based Indices
}

\author{
Alain Tchakoutio Sandjon 1,2,3*, Armand Nzeukou ${ }^{2}$ \\ ${ }^{1}$ Laboratory of Environmental Modelling and Atmospheric Physics, University of Yaoundé I, Yaoundé, Cameroon \\ ${ }^{2}$ Laboratory of Industrial Systems and Environmental Engineering, Fotso Victor University Institute of Technology, \\ Bandjoun, Cameroon \\ ${ }^{3}$ Department of Computer Science including Basic Sciences, Higher Technical Teacher's Training College Kumba, \\ University of Buea, Buea, Cameroon \\ Email: *stchakoutio@yahoo.com
}

How to cite this paper: Sandjon, A. T., \& Nzeukou, A. (2020). On the Study of the Spatio-Temporal Variations in Intensity of 30 - 60-Day Intraseasonal Rainfall Oscillations in Central Africa Using Wavelet-Based Indices. Journal of Geoscience and Environment Protection, 8, 15-32.

https://doi.org/10.4236/gep.2020.82002

Received: October 25, 2019

Accepted: January 19, 2020

Published: January 22, 2020

Copyright (๑) 2020 by author(s) and Scientific Research Publishing Inc. This work is licensed under the Creative Commons Attribution International License (CC BY 4.0).

http://creativecommons.org/licenses/by/4.0/

\begin{abstract}
The intraseasonal timescale is attractive in Central Africa (CA) where socio-economic activities are highly based on rainfall. The parameterization of intraseasonal oscillations (ISO) then remains a great challenge for the improvement of sub-seasonal to seasonal (S2S) prediction in this region. In this paper, we applied wavelet analysis on the $2.5^{\circ} \times 2.5^{\circ}$ daily Outgoing Longwave Radiation (OLR, used here as rainfall proxy) to study the variations in the intensity of the 30 - 60-day intraseasonal rainfall oscillations over Central Africa within the last three decades (1980-2009). Results showed that the mean ISO intensity (ISOI) strongly fluctuates from day to another. The plots of monthly mean ISOIs revealed that the ISO activity is highly seasonal with above-normal ISO intensity during December-May and below-normal activity during June-November. The analysis of yearly mean ISOI showed that the ISOI exhibits strong interannual variations with the years of very low ISOIs such as 1982, 1994, 2001, 2007, 2009, 2015 and the years of very high ISOIs such as $1981,1985,1986,989 / 1990,1997,2003,2005$. The regression analysis between ISOI and El Niño Southern Oscillation (ENSO) indices showed that even though the relationship between ISO and ENSO is nonlinear, warm ENSO (El Niño) events tend to reduce the ISOIs while cold ENSO (La Niña) events tend to increase it.
\end{abstract}

\section{Keywords}

Rainfall, Intraseasonal Oscillations, Intensity, Wavelet Analysis 


\section{Introduction}

In many African countries, the economic activities of the population are highly rainfall dependent. The rainfall variation, in terms of the annual cycle and interannual variability, is a source of vulnerability in the region. In Central Africa (CA) for example, the main sources of income in several families are agriculture and livestock. However since many decades, one of the crucial problems generally faced by farmers is the ability to predict the rainfall distribution within a season.

The zone called CA in this study extends from $15^{\circ} \mathrm{S}-15^{\circ} \mathrm{N}$ and $5^{\circ} \mathrm{E}-45^{\circ} \mathrm{E}$ and essentially covers the land and part of Atlantic and Indian oceans on its edges. Meteorologically speaking, it is a very interesting zone because it is quite various, both in relief and surface conditions (Tchakoutio et al., 2012). These factors may allow the rainfall to vary within very short distances (Figure 1). Unfortunately until now, CA represents a serious gap in climate variability studies, especially at intraseasonal timescales.
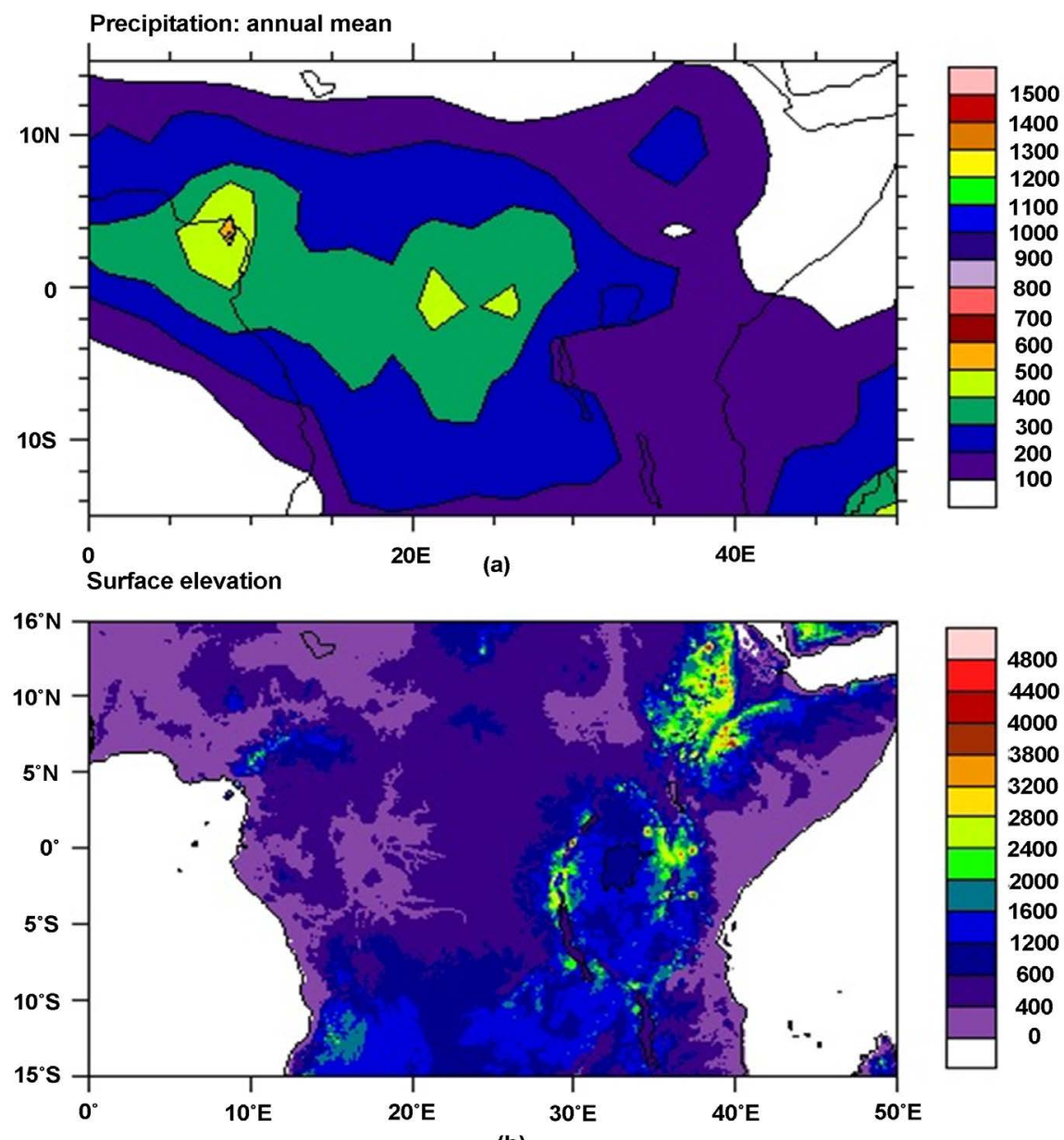

(b)

Figure 1. (a) Annual mean rainfall in CA, the plot is based $2.5^{\circ} \times 2.5^{\circ}$ pentad GPCP precipitation $(\mathrm{mm})$ for the period 1981-2000. (b) Surface elevation over the study area based on 30-min topographic data (meter) from digital elevation model (DEM) of the US Geological Survey. 
Until the years 1960s, the low resolution data, as well as the poor mathematical tools allowed the study of the rainfall variability in the tropics only at large temporal scales, especially the annual cycle and interannual variability. But since the beginning of 1970s, the availability of satellite data led the researchers to the development higher resolution satellite-based products (Arkin \& Meisner, 1987; Rao et al., 1997; Arkin \& Xie, 1997; Huffman et al., 1997; Huffman et al., 2001; Adler, 2003; McCollum et al., 2003; Huffman et al., 2009). Consequently, the researchers developed some powerful mathematical techniques to study the rainfall variability within a season. The notion of intraseasonal timescale then raised in the scientific community and since then, many authors studied the characteristics of intraseasonal rainfall variability in some regions in the tropics (e.g. Madden \& Julian, 1971; Madden \& Julian, 1972; Anderson et al., 1984; Madden \& Julian, 1994; Sultan \& Janicot, 2001; Jury \& Mpeta, 2001; Tazalika \& Jury, 2008; Maloney \& Jeffrey, 2008; Tchakoutio et al., 2012; Tchakoutio et al., 2013a; Tchakoutio et al., 2013b; Tchakoutio et al., 2014). But the documentation on intraseasonal variability in tropical Africa is highly based on West Africa, East Africa and Southern Africa (e.g. Sultan \& Janicot, 2001; Jury \& Mpeta, 2001; Sultan \& Janicot, 2003; Camberlin \& Pohl, 2006; Tazalika \& Jury, 2008; Janicot \& Sultan, 2004; Janicot et al., 2011). This confirms that CA a serious gap in the study of the tropical climate variability, though it is well-known that the intraseasonal modes such as MJO can substantially modulate rainfall variability at various timescales. In recent years, some authors started addressing the problem (Tchakoutio et al., 2012, 2013a, 2013b, 2014), but in spite of their findings, the key challenge remains the best parameterization of ISOs for their use in the improvement of the rainfall prediction in tropical Africa.

The Madden-Julian Oscillation (MJO) has been proved by several authors to dominate tropical variability on timescales of approximately 30 - 60 days (Madden \& Julian, 1972; Madden \& Julian, 1994; Matthews, 2000; Lau \& Chan, 1983; Lau \& Chan, 1986; Tchakoutio et al., 2012). As the MJO modulates deep convection in the tropics, it has strong impacts on many climate phenomena at different spatial and temporal scales. Some examples can include the onset and break of the summer monsoons (Yasunari, 1979), the formation of tropical cyclones (Liebmann et al., 1994; Maloney \& Hartmann, 2000; Bessafi \& Wheeler, 2006) and the onset and decay of some ENSO events (Kessler, 2001).

Until now in the climate studies, one of the greatest challenges remains how to effectively take into account the MJO in climate models. In general many studies carried out on MJO parameterization consisted of assigning to the whole globe or a region of the globe, a single index which describes the ISO variations over the entire region. This index is most often derived from the Principal Components Analysis of the OLR or wind data, where one or two principal components are retained (e.g Kessler, 2001; Tchakoutio et al., 2012). But in the regions such as Central Africa where climatic parameters sometimes vary drastically from one point to another, the ideal would be to construct a gridded dataset of ISOIs, at different time scales (daily, monthly, etc.). This might significantly improve re- 
gional climate forecasts in CA.

This paper addresses the variations in the 25 - 70-day ISOI in Central Africa using wavelet analysis. The data time series of daily ISO intensity is firstly built using wavelet transform, and we further performed the analyses on the resulting dataset at different time scales.

The work is organized as follows: in the next section, the data and method of analysis will be described. Section 3 shows the relevant results obtained and their analyses. Finally, the paper ends with Section 4 that presents the summary and conclusions.

\section{Data and Methods}

As stated earlier, one of the great obstacles for the study of the intraseasonal rainfall variability in Africa has so far been the availability of high resolution rainfall data. But since the advent of satellite measurements, the satellite-based data are of great interest. Amongst these products, some are very attractive because of their good temporal and spatial resolutions. Moreover some satellite data have been proved to have linear relationship with rainfall and are then more often used as rainfall proxy. One of these rainfall proxies, used in this study is the daily Outgoing Longwave Radiation (OLR) at $2.5^{\circ} \times 2.5^{\circ}$ latitude-longitude resolution (Gruber \& Krueger, 1984; Liebmann \& Smith, 1996). It is well known that in the tropics, deep convection and rainfall can be estimated through low OLR values (values less than a well-chosen threshold). This observation led many authors to the use of OLR in the estimation of rainfall (Arkin \& Meisner, 1987; Arkin \& Xie, 1997; Yoo \& Cartoon, 1988).

The Global Precipitation Climatology Project $2.5^{\circ} \times 2.5^{\circ}$ rainfall data is also used in this study. In fact it is a merged product obtained by combining the satellite estimates and gauge measurements using a weighted average (Huffman et al., 1997; Huffman et al., 2001; Adler, 2003). The GPCP products has been validated by many authors at regional and global scales (Mccollum et al., 2003) and are more and more used in place of gauge observations or supplement to gauge observations. But they are not generally used for long-term studies because of short time coverage.

To quantify the strength of ENSO and extract individual El Niño and La Niña events, the monthly Niño-3.4 region $\left(5^{\circ} \mathrm{S}-5^{\circ} \mathrm{N}, 160^{\circ} \mathrm{E}-150^{\circ} \mathrm{W}\right)$ sea surface temperature anomaly (SSTA) index is used (Trenberth, 1997). These data can be found on the NOAA website.

In many studies in geophysics, some frequencies are of greater interest than others. The filtering technique is then used to isolate the desired frequencies and attenuate the others generally called noise. In this study we used the Lanczos filter (Lanczos, 1956; Duchon, 1979). Its main advantage is the reduction of Gibb's oscillation.

Fourier transform is a technique that allows us to know the contribution of different frequencies to a given signal. This process is called the spectral analysis. The Fourier transform, $X(f)$, of a given function $x(t)$ can be written as: 


$$
X(f)=\int_{-\infty}^{+\infty} x(t) \mathrm{e}^{-j \cdot 2 \pi f t} \mathrm{~d} t
$$

In atmospheric sciences, we generally deal with time series, not an analytical function that we can be easily integrated. This means that taking a Fourier transform of discrete data simply turn into taking the discrete approximation to the Fourier integrals. For a given signal $x(n)$, the discrete Fourier transform $x(n)$ can be calculated as follows:

$$
X(n)=\sum_{k=0}^{N-1} x(n) \mathrm{e}^{-j 2 \pi \frac{k}{N} n}
$$

where $N$ is the number of signal samples. In general $x(n)$ and $X(n)$ have the same dimensions.

By this process the Fourier transform will generate values of amplitudes and phases averaged over the entire time series for each frequency component. At last, the amplitude and phase of the signal can then be represented as a function of the frequency.

The wavelet analysis is very useful in signal processing for numerical analysis discrete time series (Daniel \& Yamatoto, 1994; Chao \& Naito, 1995; Torrence \& Campo, 1998). Its main feature is the time-frequency decomposition. It is a very powerful tool for harmonic analysis, because unlike the classical Fourier analysis which allows just the transformation of time series from the time-space into the time-frequency space, the wavelet analysis is able determine both the dominant time scales of variability and how they vary with time. The detailed literature on wavelet transform can be found in Torrence \& Campo (1998). After applying wavelet transform on our 30 - 60-day filtered daily OLR time series, we obtained for each grid point the wavelet spectrum, giving for each period (frequency) and for each day, the value of wavelet power (Figure 2). We then used the criteria of maximum power to determine the daily ISOI. In fact we considered that the ISO intensity corresponding to a given day is highest wavelet power corresponding to this day. The procedure is applied to all grid points in the study area to obtain the daily ISOI. By this algorithm we have built a dataset of the ISOIs, with the same dimensions as the original time series.

For a discrete sequence $x(n)$, the wavelet transform $W_{n}(s)$ is defined as the inner convolution of $x(n)$ with a scaled and translated version of $\psi(t)$.

$$
W_{n}(s)=\sum_{n^{\prime}=0}^{N-1} x_{n^{\prime}} \psi^{*}\left[\frac{\left(n^{\prime}-n\right) \delta t}{s}\right]
$$

where $s$ is the "dilation" parameter used to change the scale, and $n$ is the translation parameter used to slide in time (Daubechies, 1990). $\delta t$ is the constant time interval between two consecutive values. The asterisk $\left.{ }^{*}\right)$ denotes complex conjugate. Then By varying the wavelet scale $s$ and translating along the localized time index $n$, one can plot an image representing both the amplitude at any scale and how this amplitude evolves with time.

Wavelet functions $\psi$ have many kinds. But for our study, we used the Morlet 

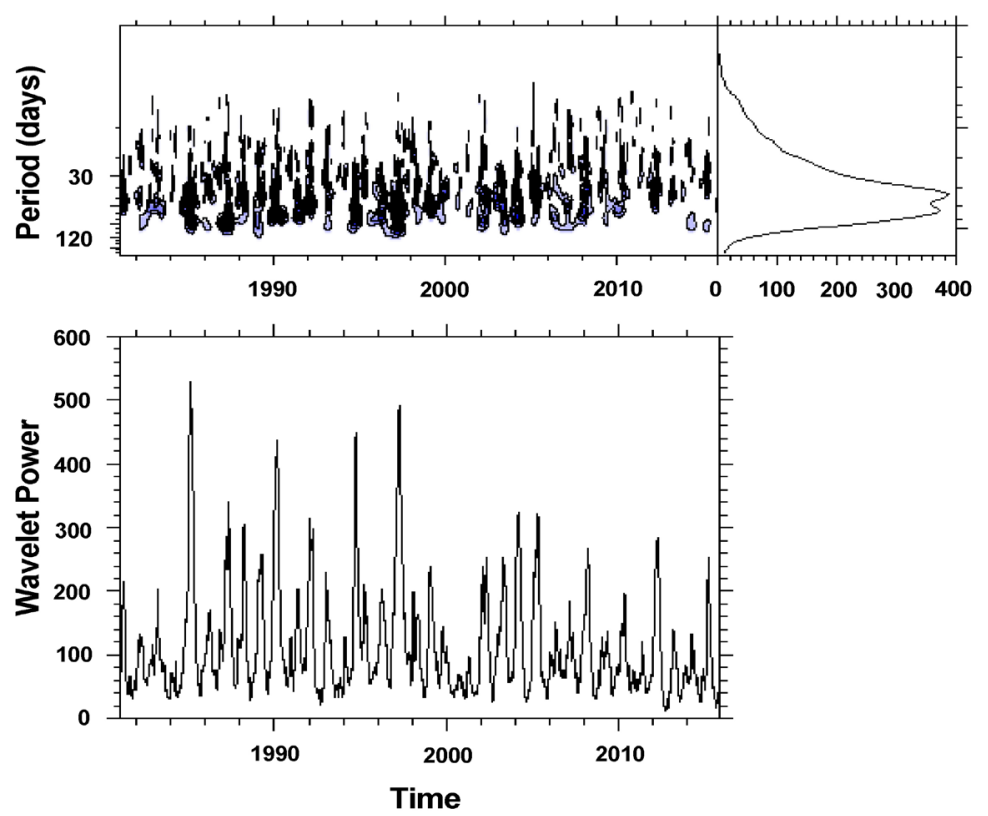

Figure 2. A case of wavelet decomposition of 25 - 70-day filtered OLR data averaged over CA (top left). Attached is the mean power spectrum that shows frequency composition of the signal (top right), and (down) the day-to-day variations of mean wavelet power within 1981-2015.

wavelet which has better local character both in time domain and in frequency domain. For $\omega_{0}>5$, the Morlet wavelet is defined as:

$$
\psi(t)=\frac{1}{\sqrt[4]{\pi}} \mathrm{e}^{i \omega_{0} t} \mathrm{e}^{-\frac{t^{2}}{2}}
$$

Then after applying wavelet transform on our 30 - 60-day filtered daily OLR time series, we obtained for each grid point the wavelet spectrum, giving for each period (frequency) and for each day, the value of wavelet power (Figure 2). We then used the criteria of maximum power to determine the period of ISO for each day. In fact we considered that the ISOI corresponding to a given day is the highest wavelet power associated with this day. This procedure is applied on all the grid points in the study area to obtain the daily ISOIs. By this algorithm we have build a dataset of the ISOIs, with the same dimensions as the original time series.

\section{Results and Discussions}

\subsection{Daily Variations}

For this study, we choose our wavelet parameters such that the scales can range from 2 to 100 days. After applying the algorithm described in Section 2 on the 30 - 60-day filtered OLR time series, we obtained the daily ISOIs time series, with the same dimensions as the original dataset. In statistics the normalization can be use to create shifted and scaled versions of statistics, where the intention is that these normalized values allow the comparison of corresponding normalized 
values for different datasets, or for datasets containing data of different scales, in a way that eliminates the effect of certain gross influences, as it is more often the case in the anomalies time series. In this study, the values of intensities obtained presented some abrupt changes from grid point to another. This caused the values of wavelet power to range from 0 to about $16,000 \mathrm{~W}^{2} / \mathrm{m}^{4}$. We then opted to normalize the time series for easy analyses. The data of each grid point form a vector, and to normalize this vector, we took the deviation from the mean in the units of standard deviation.

$$
\tilde{x}=\frac{x-\bar{x}}{\sigma}
$$

where $\tilde{X}$ is the normalized value of $x, \bar{x}$ the mean, and $\sigma$ the standard deviation of the grid data time series.

Figure 2 shows the day-to-day variations of the ISOI within 1981-2015. It can clearly be seen on this figure that the ISO strength undergoes severe changes from day to another. The long-term average daily ISO intensity ranged from 0 to $530 \mathrm{~W}^{2} / \mathrm{m}^{4}$. A peak of ISO activity is observed at the beginning and end of the year (December-May). There are some years with very high signal such as 1980, 1985, 1990 and the years of very low signal such as 1982, 1984, 1994, and 2001. Many studies carried on variations in the characteristics of intra-seasonal oscillations have been made on a global scale. In addition, almost all these studies have been carried out at global scale. Generally the authors associated to the entire globe or region a single index to describe the variations of the intraseasonal oscillations. The advantage of the present study is that it makes it possible to associate with each grid point an index, making it easier to study the spatio-temporal variations of ISO activity.

Figure 3 shows the monthly mean ISO intensity within the year. In this figure one can observe that the ISO activity is highly seasonal, as ISOI peaks during December-May and minimizes during June-November. It is clear from this figure that the ISO activity is cyclical throughout the year. In fact one can note a zone of maximum activity ISO forms a loop on the Congo Basin in December, and this loop extends to the southwestern Tanzania until the Indian Ocean on East Africa borders. This zone of maximum intensity expands gradually within the year to disappear in May, giving chance to a low ISOI zone. At the center of this zone, one can see that the ISO activity evolves the opposite way, that is, the ISO activity at the center is high during December-May and lower during JuneNovember. But this zone is very small and we can therefore consider that it does not influence the seasonality of ISO. One can emphasize our analysis by averaging the ISO intensity in the whole CA for each month. The box plot is a standardized way of displaying the distribution of data based on the five number summaries: minimum, first quartile, median, third quartile, and maximum. Figure 4 shows the box plots of the monthly ISO intensity climatology. From this figure, one can confirm that the ISO activity in Central Africa is highly seasonal. The high ISO season December-May is mainly a continuous single season. In fact, it 
is clear that the mean ISO intensity is above-normal (positive) during December-May and below-normal (negative) during June-November (Table 1). The highest amplitudes of variations (Maximum-minimum) are also observed during December-May for almost all months.

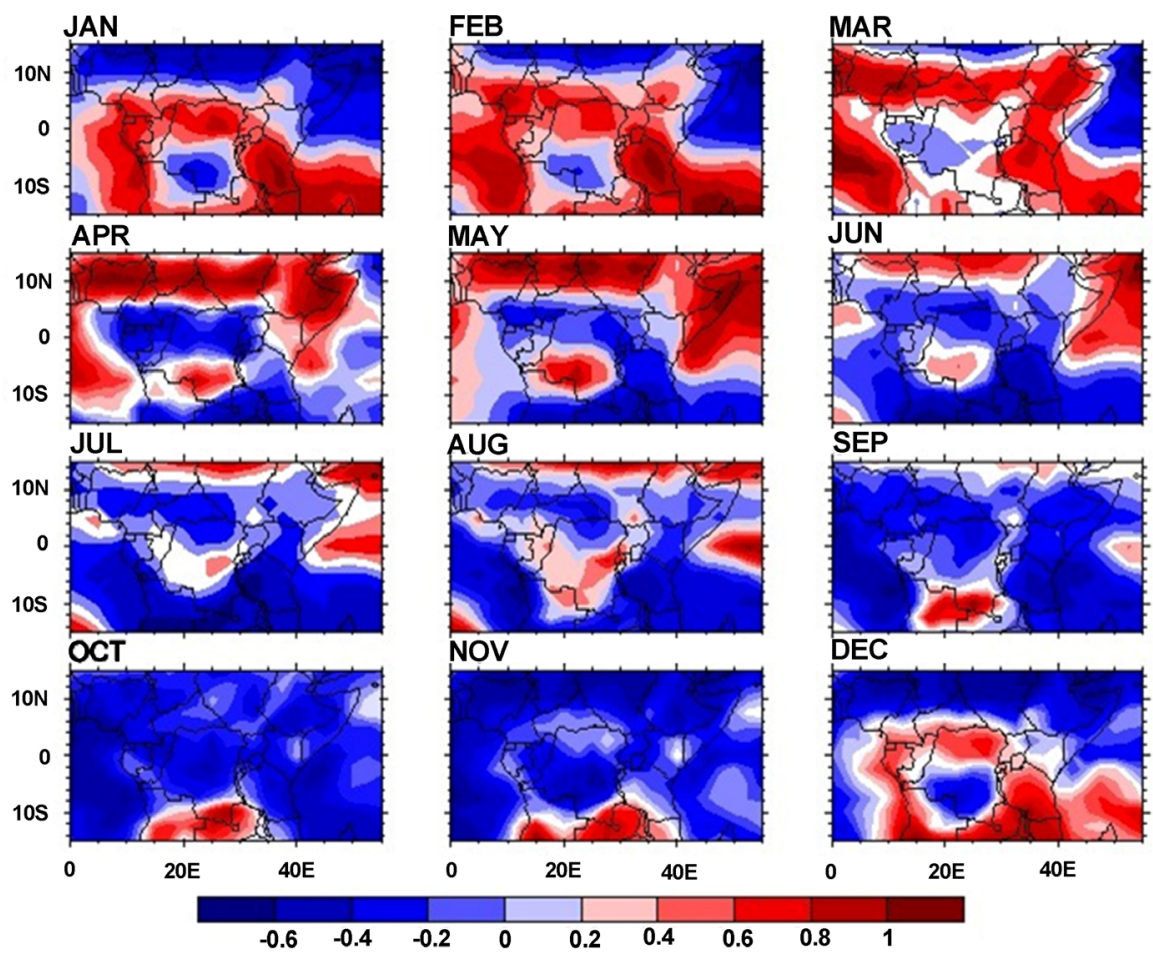

Figure 3. Monthly mean ISO intensity averaged within 1981-2009. The values are dimensionless and the corresponding months are indicated at the left top of each plot.

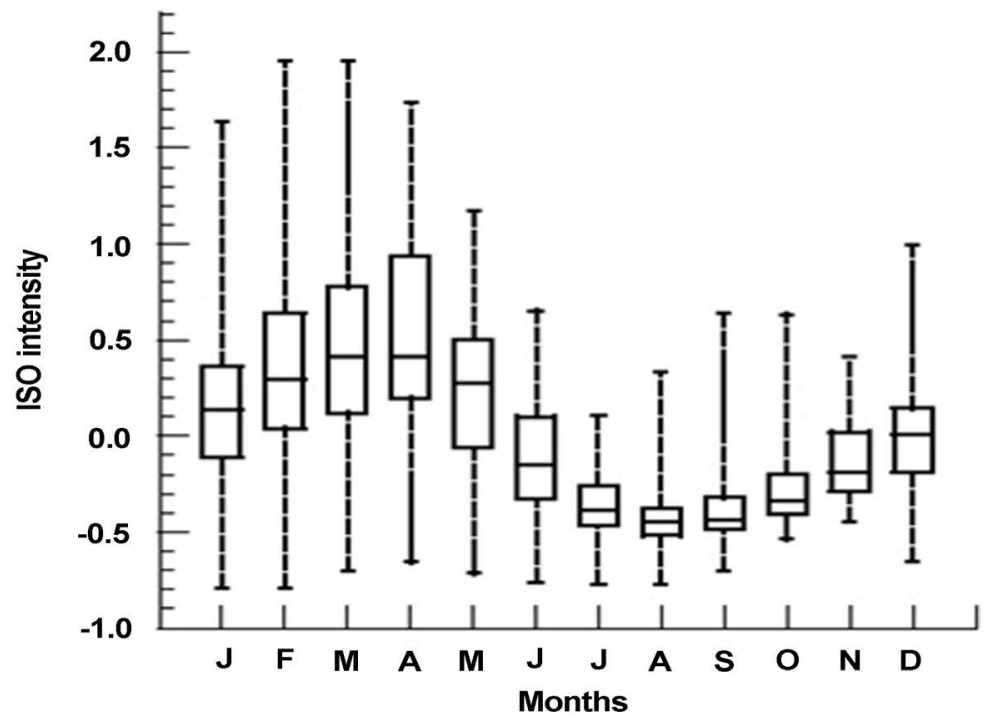

Figure 4. Box plots of the long-term monthly normalized ISOI (dimensionless). The central mark on each box represents the median value. The edges of the boxes denote the 25th and the 75th percentile. Boxes extend to extreme values to show the amplitude of the statistical distribution. 
Table 1. Statistics of the monthly mean ISOIs (normalized values) over CA within the study period.

\begin{tabular}{cccccc}
\hline Month & Mean & Standard deviation & Minimum & Maximum & State \\
\hline JAN & 0.18 & 0.41 & -0.79 & 1.63 & Above-normal \\
FEB & 0.34 & 0.50 & -0.79 & 1.95 & Above-normal \\
MAR & 0.47 & 0.52 & -0.69 & 1.95 & Above-normal \\
APR & 0.48 & 0.49 & -0.65 & 1.73 & Above-normal \\
MAY & 0.23 & 0.38 & -0.71 & 1.17 & Above-normal \\
JUN & -0.12 & 0.26 & -0.76 & 0.65 & Below-normal \\
JUL & -0.35 & 0.16 & -0.77 & 0.10 & Below-normal \\
AUG & -0.43 & 0.14 & -0.76 & 0.32 & Below-normal \\
SEP & -0.38 & 0.20 & -0.70 & 0.63 & Below-normal \\
OCT & -0.26 & 0.21 & -0.53 & 0.63 & Below-normal \\
NOV & -0.13 & 0.20 & -0.44 & 0.41 & Below-normal \\
DEC & 0.08 & 0.28 & -0.65 & 1.02 & Above-normal \\
\hline
\end{tabular}

\subsection{Interannual Variations and Relationship with ENSO}

One aspect of ISO studied so far is the interannual variations of ISO activity and its relation with low-frequency phenomena such as ENSO. These interannual variations include several parameters such as the amplitude (intensity), the frequency, the speed and the direction of propagation of the oscillations. But the present study focuses only on the intensity of the oscillations. The investigation of the interannual variations of the ISO intensity has already caught the attention of many previous authors in different regions of the globe (Madden \& Julian, 1994; Hendon \& Liebmann, 1990; Hendon et al., 1999; Slingo et al., 1999; Zhang et al., 1999; Harry \& Matthew, 2004; Tchakoutio et al., 2012, 2013b). But as stated in the introduction, in general, these studies consisted of assigning to the whole globe or a region of the globe, a single index which describes the ISO variations over the entire region. This index is generally derived from the Principal Components Analysis of the OLR or wind data, where one or two principal components are retained. But in the regions such as Central Africa where climatic parameters sometimes vary drastically from one point to another, the ideal would be to construct a gridded dataset of ISOI indices, at different time scales (daily, monthly, etc.). This would significantly improve regional climate forecasts in CA. The wavelet analysis used in the present study may seem to be a very attractive tool for this purpose. It allows us to obtain the spatio-temporal distribution of ISO (here given by the wavelet power).

Figure 5 presents the year-to-year spatial structures of the normalized ISOIs, within our study period. As can be seen on this figure, the spatial distribution of the ISOI varies considerably from one year to another, with some zones of high ISO activity and others corresponding to lower ISO activity. The strong ISO activities are generally observed in Northern Congo, over Ethiopia, and Southwestern 

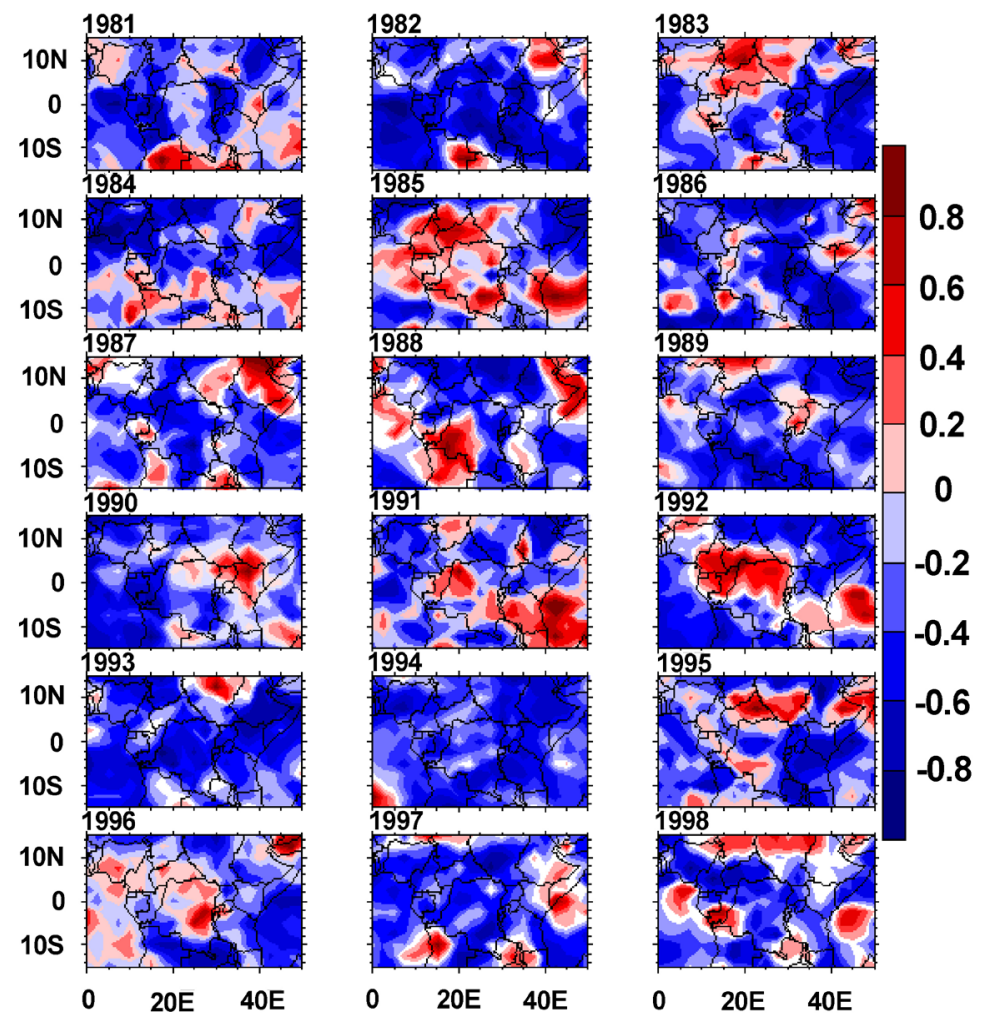

(a)
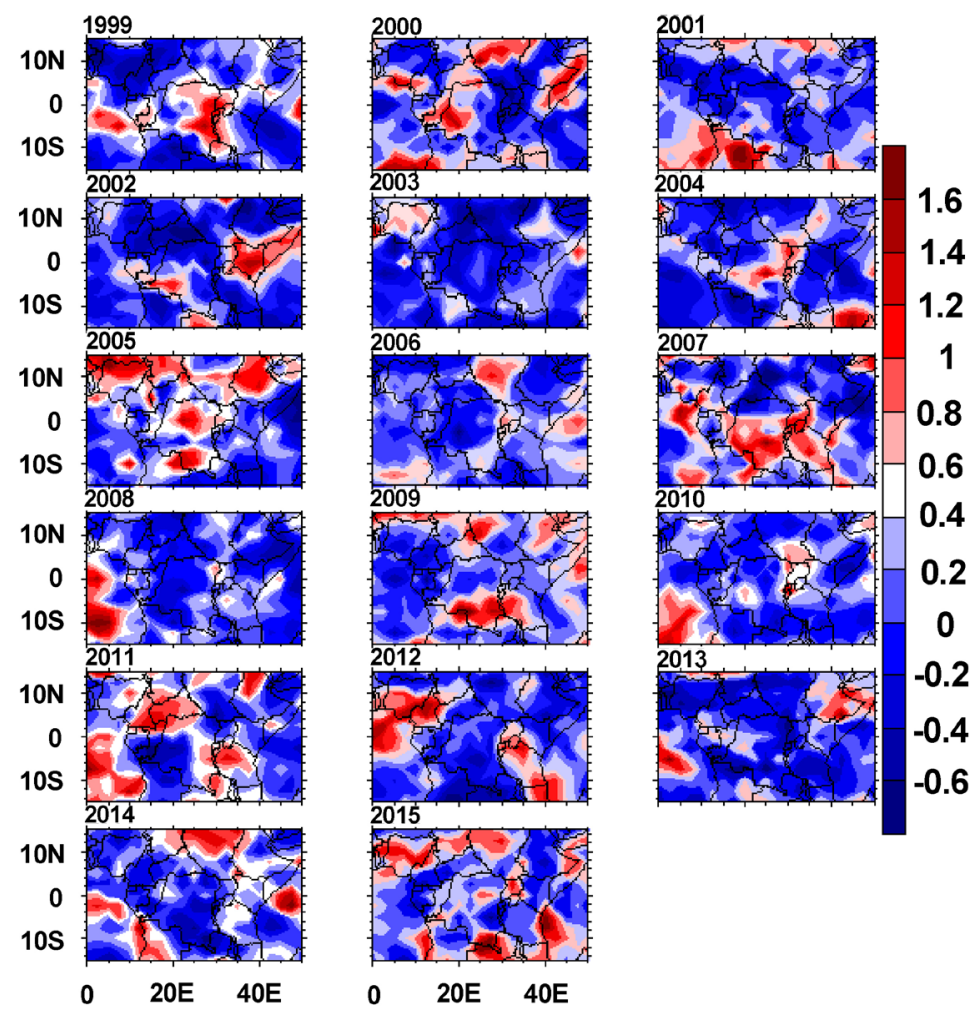

(b)

Figure 5. Yearly mean ISOI in the study area for the years 1981-2015. The intensity is dimensionless, because the data have been normalized. The corresponding year is indicated at the left top of each plot. 
Tanzania, extending to the Indian Ocean. This result seems consistent with the work of Tchakoutio et al. (2012), who documented three dominant modes of intraseasonal variability in $\mathrm{CA}$, with spatial loadings centered respectively over northern Congo, southern Ethiopia, and southwestern Tanzania, respectively. There are some years where ISOI seems to be very high, such as 1980, 1985, 1990/1991, 2000 and the years where ISO intensity looks extremely low such as 1982, 1983, 1986, 1993/1994, 1997/1998, 2002, 2003, 2008. Many authors attempted to investigate the interannual modulation of ISO activity by low frequency phenomena such as ENSO in different geographical locations on the earth (e.g. Vincent et al., 2008; Takayabu et al., 1999; Tchakoutio et al., 2012). Almost all these studies documented a nonlinear relationship between ISO activity and ENSO, but it was proved that the extremely cold ENSO years generally corresponds to very high ISO activity and the extremely warm ENSO years are more often associated with low ISO signal (Tang \& Yu, 2008; Tchakoutio et al., 2012; Tchakoutio et al., 2013b).

Nowadays the oceanic Niño index is mostly used for identifying El Niño (warm ENSO) and La Niña (cool ENSO) events in the in the tropical Pacific. For simplicity, the threshold method is applied to identify the years of warm ENSO (El Niño) and the years of cold ENSO (La Niña). We normalized all values of ENSO index for easy comparison, by taking the deviation from the mean in the units of standard deviation. A year should be considered as warm ENSO when the index is greater than +0.7 standard deviation and cold ENSO when the index is lower than -0.7 standard deviation. The neutral years correspond to an ENSO index between +0.7 and -0.7 standard deviation. Following this threshold method described above, the warm ENSO years selected are 1982, 1983, 1992, 1997, and the cold ENSO years are 1985/1986, 1989/1990, 1999/2000 and 2008/2009.

Figure 6 shows year-to-year evolution of the normalized mean ISOI in CA, as well as the normalized Niño-3.4 SST indices for the period 1981-2015. In this figure, one can note a strong year-to-year variations in the ENSO index, especially within the decades 1981-1990 and 1991-2000. The ENSO varied less during the last two decades (2001-2015). The ISOI evolves the same way, exhibiting the highest variations during the first two decades of our study period. One can then note in Figure 6 that the warm ENSO years generally correspond to below-normal ISO intensity and the cold ENSO years to above-normal ISO intensity. This remark can be further highlighted in Table 2 that displays interannual variations of the ISOI and ENSO indices within the study period. Figure 7 shows the scatter plots and the regression line between the Normalized ISOI and ENSO indices. The regression line has a negative slope confirming that warm SSTs tends to reduce the ISOI while warm SSTs tends to increase ISOI. However the low values of the correlation coefficients indicate that the relationship between ISO periods and ENSO is nonlinear. In fact the ISO and ENSO are atmospheric and oceanic modes of variability with different timescales, thus their relationship is most likely nonlinear. Nevertheless the correlation coefficient increases from -0.17 to -0.28 when we consider only the extreme ENSO years (El Niño and La Niña) 


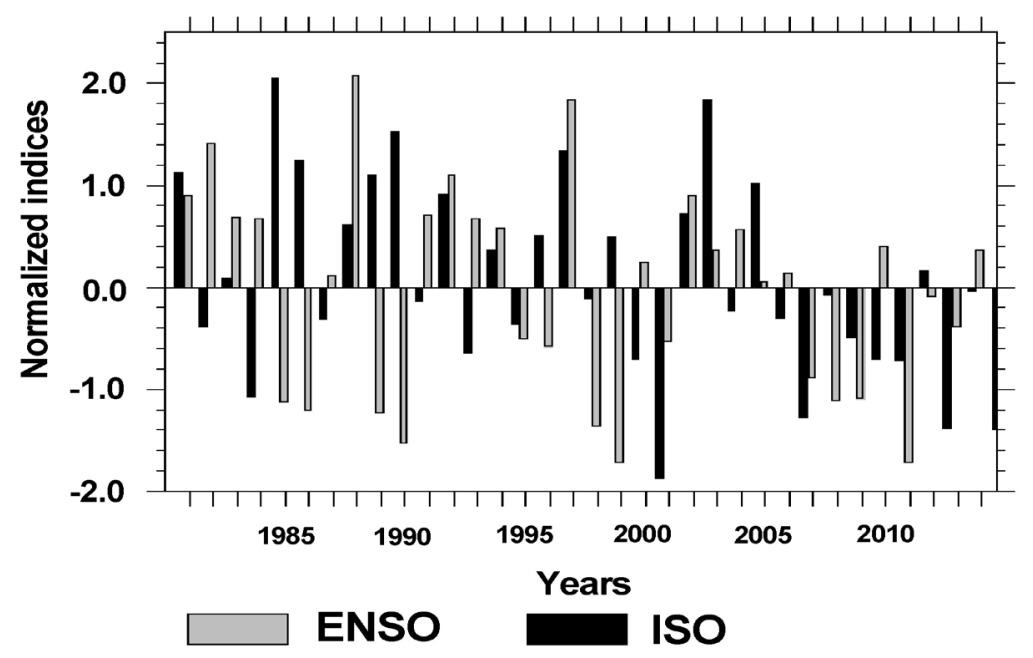

Figure 6. Normalized ISOI and Nino3.4 indices for the study period 1981-2015.
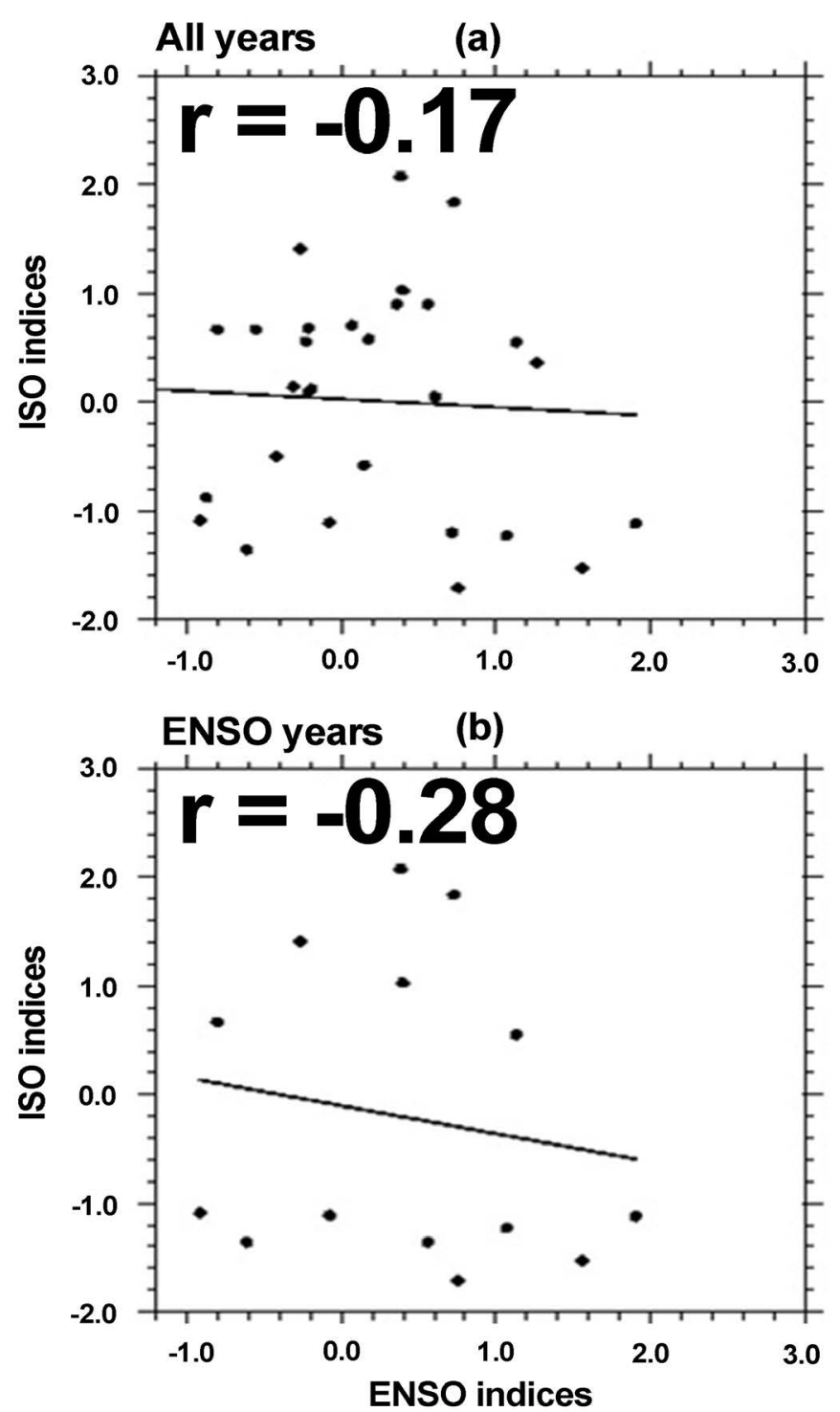

Figure 7. Regression between ENSO indices and the normalized ISOI. 
Table 2. Interannual variations of the ISOI and ENSO indices for the years 1980-2009. All the values are dimensionless because the fields have been normalized for easy comparison. The warm and cold ENSO indices are marked with star for clarity.

\begin{tabular}{|c|c|c|c|c|}
\hline Year & Normalized ISOI & Status & Normalized ENSO index & Status \\
\hline 1980 & 1.16 & Above-normal & 0.55 & Neutral \\
\hline 1981 & 0.55 & Above-normal & 0.9 & Neutral \\
\hline 1982 & -1.62 & Below-normal & $1.41^{*}$ & Warm \\
\hline 1983 & 0.01 & Above-normal & 0.68 & Neutral \\
\hline 1984 & -0.47 & Below-normal & 0.67 & Neutral \\
\hline 1985 & 2.01 & Above-normal & $-1.12^{*}$ & Cold \\
\hline 1986 & 0.80 & Above-normal & $-1.2^{*}$ & Cold \\
\hline 1987 & 0.02 & Above-normal & 0.12 & Neutral \\
\hline 1988 & 0.03 & Above-normal & $2.08^{*}$ & Warm \\
\hline 1989 & 1.02 & Above-normal & $-1.23^{*}$ & Cold \\
\hline 1990 & 1.66 & Above-normal & $-1.53^{*}$ & Cold \\
\hline 1991 & 0.33 & Above-normal & 0.71 & Neutral \\
\hline 1992 & -1.44 & Below-normal & $1.03^{*}$ & Warm \\
\hline 1993 & -0.38 & Below-normal & 0.67 & Neutral \\
\hline 1994 & 0.41 & Above-normal & -0.58 & Neutral \\
\hline 1995 & -0.1 & Below-normal & -0.5 & Neutral \\
\hline 1996 & 0.39 & Above-normal & -0.58 & Neutral \\
\hline 1997 & -0.1 & Below-normal & $1.84^{*}$ & Warm \\
\hline 1998 & 0.01 & Above-normal & 0.10 & Neutral \\
\hline 1999 & 1.01 & Above-normal & $-1.71^{*}$ & Cold \\
\hline 2000 & -0.31 & Below-normal & $-1.36^{*}$ & Cold \\
\hline 2001 & 0.12 & Above-normal & 0.53 & Neutral \\
\hline 2002 & -1.21 & Below-normal & $1.01^{*}$ & Warm \\
\hline 2003 & 0.07 & Above-normal & 0.36 & Neutral \\
\hline 2004 & 0.00 & Above-normal & 0.56 & Neutral \\
\hline 2005 & 0.59 & Above-normal & 0.05 & Neutral \\
\hline 2006 & -0.04 & Below-normal & 0.14 & Neutral \\
\hline 2007 & -0.61 & Below-normal & -0.88 & Neutral \\
\hline 2008 & 0.06 & Above-normal & $-1.11^{*}$ & Cold \\
\hline 2009 & -0.63 & Below-normal & $-1.09^{*}$ & Cold \\
\hline 2010 & -0.55 & Below-normal & 0.21 & Neutral \\
\hline 2011 & -0.56 & Below-normal & -1.83 & Cold \\
\hline 2012 & 0.03 & Above-normal & -0.02 & Neutral \\
\hline 2013 & -1.22 & Below-normal & -0.41 & Neutral \\
\hline 2014 & -0.01 & Below-normal & 0.16 & Neutral \\
\hline 2015 & -1.23 & Below-normal & 2.08 & Warm \\
\hline
\end{tabular}


described above. Figure 8 displays the mean ISOI for Warm ENSO and cold ENSO years, as well as the difference between the two values, for each grid point of our study area. As could be expected from the previous analyses, the difference is positive almost all over the study area, confirming that the average ISOI is higher for La Niña years, when compared with El Niño years.

\section{Summary and Conclusion}

The primary objective of this study was to investigate the spatiotemporal variations in the 25 - 70-day ISO intensity in Central Africa based on wavelet analysis. For this purpose we used as rainfall proxy the $2.5^{\circ} \times 2.5^{\circ}$ daily OLR datasets within the period 1981-2015.

In our analysis we choose Morlet wavelet and we took the parameters such that the period of the oscillations span from 2 days to 109.86 days. But we limited the period from 25 days to 70 days by Lanczos filtering. For each day of the study period, we obtained the values of wavelet power corresponding to each period (frequency) between 2 and 109.86 days and we retained for this day the maximum value of wavelet power that falls within this period range. Through this algorithm, the values of ISO intensity obtained vary between 0 to about $16,000 \mathrm{~W}^{2} / \mathrm{m}^{4}$. That is why opted to normalize the time series for easy analyses.

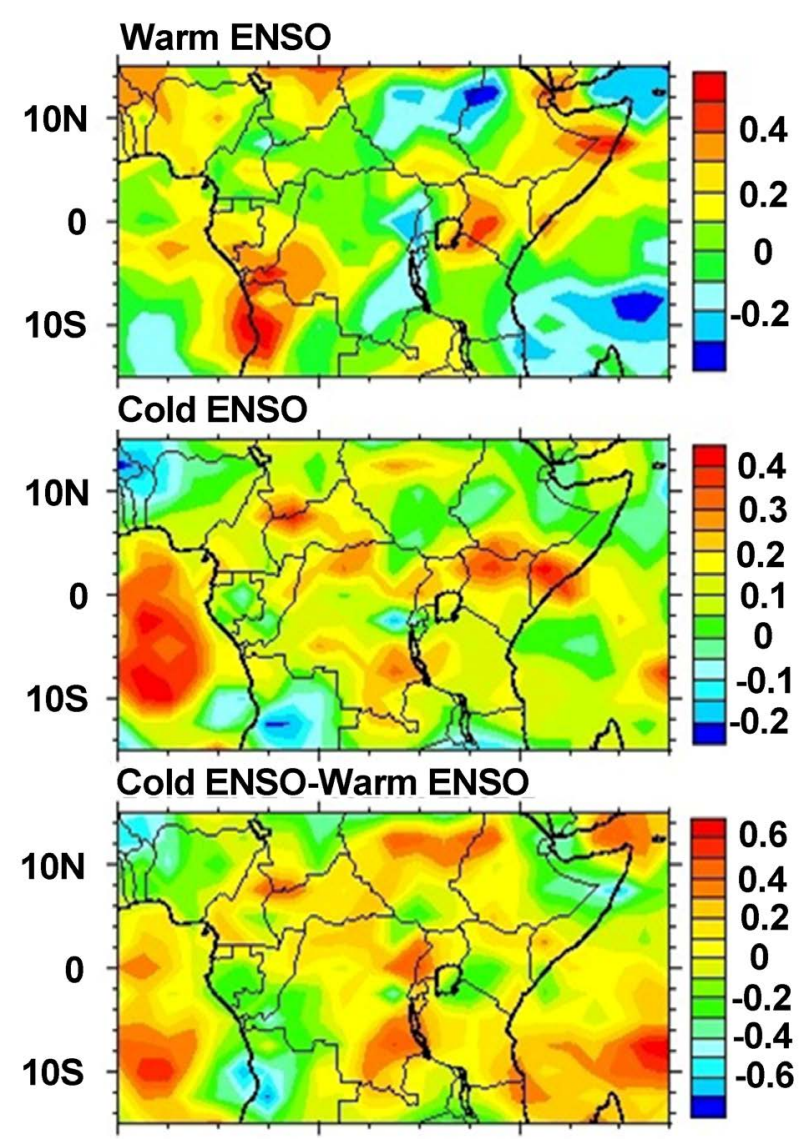

Figure 8. Mean normalized ISOI for Warm and cool ENSO years, and the difference between Warm and cold ENSO years. 
For each grid point, we then took the deviation from the mean in the units of standard deviation. Though this algorithm, we built a dataset of normalized daily ISOI and this dataset has been subjected to some statistical analysis to extract relevant information.

The plot of daily mean ISO intensity revealed that the ISO intensity highly fluctuates from day to another, in accordance with some previous studies. The analysis of monthly mean ISO periods showed that ISO activity is highly seasonal, with above-normal ISO activity during December-May, and below-normal ISO activity during June-November. We also investigated the interannual variations of ISO activity, and we found out that the ISO intensity undergoes large interannual variations with some years of very strong ISO activity and years of low ISO activity. The plots of ISO intensity and ENSO indices showed that the relationship between the two quantities is not linear, but nevertheless it is clear that the extremely warm ENSO (El Niño) years generally correspond to below-normal ISO activity and the extremely cold ENSO (La Niña) years are often associated with above-normal ISO activity. While we are still looking for a good model for the parameterization of ISO, the main challenge remains the use of the relationship MJO-ISO to considerably improve the regional and global climate models in the tropics.

\section{Conflicts of Interest}

The authors declare no conflicts of interest regarding the publication of this paper.

\section{References}

Adler, R. F. (2003). The Version-2 Global Precipitation Climatology Project (GPCP). Monthly Precipitation Analysis (1979-Present). Journal of Hydrometeor, 4, 1147-1167. https://doi.org/10.1175/1525-7541(2003)004<1147:TVGPCP >2.0.CO;2

Anderson, J. R., Stevens, D. E., \& Julian, P. R. (1984). Temporal Variations of the Tropical 40-50-Day Oscillation. Monthly Weather Review, 112, 2431-2438. https://doi.org/10.1175/1520-0493(1984)112<2431:TVOTTD >2.0.CO;2

Arkin, P. A., \& Meisner, N. (1987). The Relationship between Large Scale Convective Rainfall and Cold Cloud over the Western Hemisphere during 1982-1984. Monthly Weather Review, 115, 51-74. https://doi.org/10.1175/1520-0493(1987)115<0051:TRBLSC>2.0.CO;2

Arkin, P. A., \& Xie, P. (1997). Global Monthly Precipitation Estimates from Satellite-Observed Outgoing Longwave Radiation. Journal of Climate, 9, 840-858. https://doi.org/10.1175/1520-0442(1996)009<0840:AOGMPU>2.0.CO;2

Camberlin, P., \& Pohl, B. (2006). Influence of the Madden-Julian Oscillation on East African Rainfall. Part I: Intraseasonal Variability and Regional Dependency. Quarterly Journal of the Royal Meteorological Society, 132, 2521-2539. https://doi.org/10.1256/qj.05.104

Chao, B. F., \& Naito, I. (1995). Wavelet Analysis Provides a New Tool for Studying Earth's Rotation. Eos, Transactions American Geophysical Union, 76, 161-165. https://doi.org/10.1029/95EO00084

Daniel, T. L. L., \& Yamatoto, A. (1994). Wavelet Analysis: Theory and Applications. Hew- 
lett Packard Journal, 44-52.

Daubechies, I. (1990). The Wavelet Transform Time-Frequency Localization and Signal Analysis. IEEE Transactions on Information Theory, 36, 961-1004. https://doi.org/10.1109/18.57199

Duchon, C. E. (1979). Lanczos Filtering in One and Two Dimensions. Journal of Applied Meteorology, 18, 1016-1022. https://doi.org/10.1175/1520-0450(1979)018<1016:LFIOAT>2.0.CO;2

Gruber, A., \& Krueger, A. F. (1984). The Status of the NOAA Outgoing Longwave Radiation Data Set. Bulletin of the American Meteorological Society, 65, 958-962. https://doi.org/10.1175/1520-0477(1984)065<0958:TSOTNO>2.0.CO;2

Harry, H. H., \& Matthew, C. W. (2004). An All-Season Real-Time Multivariate MJO Index: Development of an Index for Monitoring and Prediction. Monthly Weather Review, 132, 1917-1932. https://doi.org/10.1175/1520-0493(2004)132<1917:AARMMI>2.0.CO;2

Hendon, H. H., \& Liebmann, B. (1990). The Intraseasonal (30-50 day). Oscillation of the Australian Summer Monsoon. Journal of the Atmospheric Sciences, 47, 2909-2292. https://doi.org/10.1175/1520-0469(1990)047<2909:TIDOOT>2.0.CO;2

Hendon, H. H., Zhang, C., \& Glick, J. (1999). Interannual Variation of the Madden Julian Oscillation during Austral Summer. Journal of Climate, 12, 2538-2550. https://doi.org/10.1175/1520-0442(1999)012<2538:IVOTMJ>2.0.CO;2

Huffman, G. J., Adler, R. F., Arkin, P. A., Chang, A., Ferraro, R., Gruber, A., Janowiak, J. E., McNab, A., Rudolf, B., \& Schneider, U. (1997). The Global Precipitation Climatology Project (GPCP). Combined Precipitation Dataset. Bulletin of the American Meteorological Society, 78, 5-20. https://doi.org/10.1175/1520-0477(1997)078<0005:TGPCPG>2.0.CO;2

Huffman, G. J., Adler, R. F., David, T. B., \& Guojun, G. D. (2009). Improving the Global Precipitation Record: GPCP Version 2.1. Geophysical Research Letters, 36, L17808. https://doi.org/10.1029/2009GL040000

Huffman, G. J., Adler, R. F., Morrissey, M., Bolvin, D., Curtis, S., Joyce, R., McGavock, B., \& Susskind, J. (2001). Global Precipitation at One-Degree Daily Resolution from Multi-Satellite Observations. Journal of Hydrometeorology, 2, 36-50. https://doi.org/10.1175/1525-7541(2001)002<0036:GPAODD>2.0.CO;2

Janicot, S., \& Sultan, B. (2004). Intra-Seasonal Modulation of Convection in the West African Monsoon. Geophysical Research Letters, 28, 523-526. https://doi.org/10.1029/2000GL012424

Janicot, S., Caniaux, G., Chauvin, F., Coetlogon, G., Fontaine, B., Hall, N., Kiladis, G., Lafore, J. P., Lavaysse, C., Lavender, S. L., Leroux, S., Marteau, R., Mounier, F., Philippon, N., Roehrig, R., Sultan, B., \& Taylor, C. M. (2011). Intraseasonal Variability of the West African Monsoon. Atmospheric Science Letters, 12, 58-66. https://doi.org/10.1002/asl.280

Jury, M. R., \& Mpeta, J. (2001). Intraseasonal Convective Structure and Evolution over Tropical East Africa. Climate Research, 17, 83-92. https://doi.org/10.3354/cr017083

Kessler, W. (2001). EOF Representations of the Madden-Julian Oscillation and Its Connection with ENSO. Journal of Climate, 14, 3055-3061. https://doi.org/10.1175/1520-0442(2001)014<3055:EROTMJ>2.0.CO;2

Lanczos, C. (1956). Applied Analysis (p. 539). Upper Saddle River, NJ: Prentice-Hall.

Lau, K. M., \& Chan, P. H. (1983). Short-Term Climate Variability and Atmospheric Teleconnections from Satellite Observed Outgoing Longwave Radiation. Part II: Simulta- 
neous Relationships. Journal of the Atmospheric Sciences, 40, 2751-2767. https://doi.org/10.1175/1520-0469(1983)040<2751:STCVAA $>2.0 . C O ; 2$

Lau, K. M., \& Chan, P. H. (1986). Aspects of the 40 - 50 Day Oscillation during the Northern Summer as Inferred from Outgoing Longwave Radiation. Monthly Weather Review, 114, 1354-1367. https://doi.org/10.1175/1520-0493(1986)114<1354:AOTDOD>2.0.CO;2

Liebmann, B., \& Smith, C. A. (1996). Description of a Complete (Interpolated). Outgoing Longwave Radiation Dataset. Bulletin of the American Meteorological Society, 77, 12751277.

Madden, R. A., \& Julian, P. R. (1971). Detection of a 40-50 Day Oscillation in the Zonal Wind in the Tropical Pacific. Journal of the Atmospheric Sciences, 28, 702-708. https://doi.org/10.1175/1520-0469(1971)028<0702:DOADOI>2.0.CO;2

Madden, R. A., \& Julian, P. R. (1972). Description of Global-Scale Circulation Cells in the Tropics with a 40-50 Day Period. Journal of the Atmospheric Sciences, 29, 1109-1123. https://doi.org/10.1175/1520-0469(1972)029<1109:DOGSCC>2.0.CO;2

Madden, R. A., \& Julian, P. R. (1994). Observations of the 40 - 50 Day Tropical Oscillation: A Review. Monthly Weather Review, 122, 814-837. https://doi.org/10.1175/1520-0493(1994)122<0814:OOTDTO>2.0.CO;2

Maloney, E. D., \& Hartmann, D. L. (2000). Modulation of Eastern North Pacific Hurricanes by the Madden-Julian Oscillation. Journal of Climate, 13, 1451-1460. https://doi.org/10.1175/1520-0442(2000)013<1451:MOENPH>2.0.CO;2

Maloney, E. D., \& Jeffrey, S. (2008). Intraseasonal Variability of the West African Monsoon and Atlantic ITCZ. Journal of Climate, 21, 2898-2918. https://doi.org/10.1175/2007JCLI1999.1

Matthews, M. (2000). Propagating Mechanisms for the Madden-Julian Oscillation. Quarterly Journal of the Royal Meteorological Society, 126, 2637-2652. https://doi.org/10.1002/qj.49712656902

McCollum, J., Nelkin, E., Klotter, D., Berte, Y., Diallo, B. M., Gaye, I., Kpabeba ,G., Ndiaye, O., Noukpozounkou, M. M., Thiam, A., Toure, A. A., Traore, A. K., Nicholson, S. E., \& Some, B. (2003). Validation of TRMM and Other Rainfall Estimates with a High-Density Gauge Dataset for West Africa. Part I. Validation of GPCC Rainfall Product and Pre-TRMM Satellite and Blended Products. Journal of Applied Meteorology, 40, 1355-1368. https://doi.org/10.1175/1520-0450(2003)042<1355:VOTAOR>2.0.CO;2

Slingo, J. M., Rowell, D. B., Sperber, K. R., \& Nortley, F. (1999). On the Predictability of the Inner Annual Behavior of the Madden-Julian Oscillation and Its Relationship with El Niño. Quarterly Journal of the Royal Meteorological Society, 125, 583-609.

Sultan, B., \& Janicot, S. (2001). Intraseasonal Modulation of Convection in the West African Monsoon. Geophysical Research Letters, 28, 523-526. https://doi.org/10.1029/2000GL012424

Sultan, B., \& Janicot, S. (2003). The West African Monsoon Dynamics. Part II: The Pre-Onset and Onset of the Summer Monsoon. Journal of Climate, 16, 3407-3427. https://doi.org/10.1175/1520-0442(2003)016<3407:TWAMDP>2.0.CO;2

Takayabu, Y. N., Iguchi, T., Kachi, M., Shibata, A., \& Kanzawa, H. (1999). Abrupt Termination of the 1997-98 El Nino in Response to a Madden-Julian Oscillation. Nature, 402, 279-282. https://doi.org/10.1038/46254

Tang, Y., \& Bin, Y. (2008). MJO and Its Relationship to ENSO. Journal of Geophysical Research: Atmospheres, 113, D14106. https://doi.org/10.1029/2007JD009230

Tazalika, L., \& Jury, M. R. (2008). Intraseasonal Rainfall Oscillations over Central Africa: 
Space-Time Character and Evolution. Theoretical and Applied Climatology, 94, 67-80. https://doi.org/10.1007/s00704-007-0349-6

Tchakoutio, A. S., Nzeukou, A., \& Tchawoua, C. (2012). Intraseasonal Atmospheric Variability and Its Interannual Modulation in Central Africa. Meteorology and Atmos pheric Physics, 117, 167-179. https://doi.org/10.1007/s00703-012-0196-6

Tchakoutio, A. S., Nzeukou, A., Tchawoua, C., Kamga, F. M., \& Vondou, D. (2013a). A Comparative Analysis of Intraseasonal Variability in OLR and 1DD GPCP Data over Central Africa. Theoretical and Applied Climatology, 116, 37-49. https://doi.org/10.1007/s00704-013-0911-3

Tchakoutio, A. S., Nzeukou, A., Tchawoua, C., Sonfack, B., \& Siddi, T. (2013b). Comparing the Patterns of 20 - 70 Days Intraseasonal Oscillations over Central Africa during the Last Three Decades. Theoretical and Applied Climatology, 118, 319-329.

Tchakoutio, A. S., Nzeukou, A., Tchawoua, C., Sonfack, B., \& Tengeleng, S. (2014). On the Differences in the Intraseasonal Rainfall Variability between Western and Eastern Central Africa: Case of 10 - 25-Day Oscillations. Journal of Climatology, 2014, Article ID: 434960. https://doi.org/10.1155/2014/434960

Torrence, C., \& Compo, G. P. (1998). A Practical Guide to Wavelet Analysis. Bulletin of the American Meteorological Society, 79, 61-78. https://doi.org/10.1175/1520-0477(1998)079<0061:APGTWA>2.0.CO;2

Trenberth, K. E. (1997). The definition of El Niño. Bulletin of the American Meteorological Society, 79, 2771-2777. https://doi.org/10.1175/1520-0477(1997)078<2771:TDOENO >2.0.CO;2

Vincent, D. G., Fink, A., Schrage, J. M., \& Speth, P. (2008). High- and Low-Frequency Intraseasonal Variance of OLR on Annual and ENSO Timescales. Journal of Climate, 11, 968-986. https://doi.org/10.1175/1520-0442(1998)011<0968:HALFIV>2.0.CO;2

Yasunari, T. (1979). Cloudiness Fluctuations Associated with the Northern Hemisphere Summer Monsoon. Journal of the Meteorological Society of Japan, 57, 227-242. https://doi.org/10.2151/jmsj1965.57.3_227

Yoo, J. M., \& James, C. (1988). Spatial Dependence on the Relationship between Rainfall and Outgoing Longwave Radiation in the Tropical Atlantic. Journal of Climate, 7, 1047-1054. https://doi.org/10.1175/1520-0442(1988)001<1047:SDOTRB >2.0.CO;2

Zhang, C., Hendon, H., \& Glick, J. (1999). Interannual Variation of the Madden-Julian Oscillation during Austral Summer. Journal of Climate, 12, 2538-2550. https://doi.org/10.1175/1520-0442(1999)012<2538:IVOTMJ>2.0.CO;2 